\title{
Association of homocysteine and methylene tetrahydrofolate reductase (MTHFR C677T) gene polymorphism with coronary artery disease (CAD) in the population of North India
}

\author{
Rajneesh Tripathi ${ }^{1}$, Satyendra Tewari ${ }^{2}$, Prabhat Kumar Singh ${ }^{3}$ and Sarita Agarwal ${ }^{1}$ \\ ${ }^{1}$ Department of Genetics, Sanjay Gandhi Post Graduate Institute of Medical Sciences, Lucknow, India. \\ ${ }^{2}$ Department of Cardiology, Sanjay Gandhi Post Graduate Institute of Medical Sciences, Lucknow, India. \\ ${ }^{3}$ Department of Anaesthesiology, Sanjay Gandhi Post Graduate Institute of Medical Sciences, Lucknow, \\ India.
}

\begin{abstract}
The implications of the methylene tetrahydrofolate reductase (MTHFR) gene and the level of homocysteine in the pathogenesis of coronary artery disease (CAD) have been extensively studied in various ethnic groups. Our aim was to discover the association of MTHFR (C677T) polymorphism and homocysteine level with CAD in north Indian subjects. The study group consisted of 329 angiographically proven CAD patients, and 331 age and sex matched healthy individuals as controls. MTHFR (C677T) gene polymorphism was detected based on the polymerase chain reaction and restriction digestion with Hinfl. Total homocysteine plasma concentration was measured using immunoassay. T allele frequency was found to be significantly higher in patients than in the control group. We found significantly elevated levels of mean homocysteine in the patient group when compared to the control group $(p=$ 0.00). Traditional risk factors such as diabetes, hypertension, smoking habits, a positive family history and lipid profiles (triglyceride, total cholesterol, HDL-cholesterol, LDL-cholesterol, VLDL-cholesterol), were found significantly associated through univariate analysis. Furthermore, multivariable logistics regression analysis revealed that CAD is significantly and variably associated with diabetes, hypertension, smoking, triglycerides and HDL-cholesterol. Our findings showed that MTHFR C677T polymorphism and homocysteine levels were associated with coronary artery disease in the selected population.
\end{abstract}

Key words: angiography, CAD, homocysteine, MTHFR polymorphism.

Received: July 13, 2009; Accepted: November 17, 2009.

\section{Introduction}

Coronary artery disease (CAD) is the consequence of atherosclerotic plaque disposition on the coronary artery wall. Its manifestation depends on interactions between environmental and genetic risk factors (Andreassi et al., 2003). Individual susceptibility to the disease has been associated with functional allelic variation. Thus, the identification of gene polymorphisms relating to the formation of atherosclerotic plaques, and consequently, thrombi, may contribute towards developing early diagnostic methods and guiding preventive procedures (Arruda et al., 1998; Doevendans et al., 2001; Andreassi et al., 2003). The gene that encodes methylene tetrahydrofolatereductase enzyme (MTHFR), which is involved in the metabolism of homocysteine (Hcy), is of great interest in clinical practice (Rob-

Send correspondence to Sarita Agarwal. Department of Genetics, Sanjay Gandhi Postgraduate Institute of Medical Sciences, SGPGIMS, 226014 Lucknow, India. E-mail: sarita@sgpgi.ac.in. inson et al., 1995; Hofmann et al., 2001; Andreassi et al., 2003). Hcy, an amino acid derived from protein catabolism, is present in the plasma in several forms, with the greatest proportion (70\%) bound to albumin (Doevendans et al., 2001). High levels of Hcy (hyperhomocysteinemia) have been identified as a risk factor for atherosclerosis (Bova et al., 1999; Hankey and Eikelboom, 1999; Lobo et al., 1999; Doevendans et al., 2001; Andreassi et al., 2003). The mechanism for the vascular lesions induced by hyperhomocysteinemia remains unclear. Experimental evidence suggests that Hcy facilitates the vascular oxidative process, thereby altering the coagulation system, and reduces the vasomotor regulation of the endothelium (Welch et al., 1997; Tyagi, 1998; Hankey and Eikelboom, 1999; Hofmann et al., 2001). The aim of this study was to assess the relationship between MTHFR gene polymorphism and plasma homocysteine level with the traditional risk factors of coronary artery disease in a north Indian population. 


\section{Material and Methods}

\section{Study subjects}

Patients, with evidence of more than $50 \%$ stenosis in coronary arteries, a past history of prior angioplasty, or CAD by-pass grafting, were included in the present study. The patients were recruited from the outpatient and inpatient services of the Department of Cardiology, SGPGIMS during the period February, 2006 to November, 2008. The study group included angiographically proven CAD patients. The control group consisted of individuals without a CAD background and with negative results in treadmillstress tests. The two groups were age and sex matched. An individual clinical background entailing the presence of diabetes, hypertension, smoking habits, CAD family history, body-mass index and complete lipid profile (serum triglycerides, total cholesterol, HDL, LDL and VLDL) were furnished by members of both the patient and control groups independently. Diabetes and hypertension was diagnosed in patients and controls, based on prior medical records or standard clinical examination and tests, according to the standard definition described by Fauci et al. (2008). Habitual smoking was defined as prevailing at least one year before CAD onset. A family history of CAD was defined based on its presence in first-degree relatives. Body-mass index was calculated by dividing the weight in kilograms by the square of the height in meters (Fouci et al., 2008). Patients and controls included in the study were natives of Uttar Pradesh. Exclusion criteria were cardiomyopathy, a febrile condition, rheumatic heart disease, congenital heart disease and systemic disorders. A prior written informed consent was obtained from patients and controls. The study was approved by an institutional ethics committee.

\section{DNA preparation and genotyping}

Genomic DNA was extracted from EDTA peripheral blood leukocytes by the standard phenol-chloroform method (Poncz et al., 1982). The quality of DNA was checked through $0.8 \%$ agarose (Sigma, USA) gel electrophoresis, and quantification was done on a UV spectrophotometer (Specgene Ltd, UK). Synthetic oligonucleotides were acquired from Genetix, France. Primers (Forward 5'TGA AGG AGA AGG TGT CTG CGG GA3', Reverse 5'AGG ACG GTG CGG TGA GAG TG3') for exon 4 of the MTHFR gene were used as described by Frost $e t$ al. (1995). Amplification was done in an automated thermocycler (BioRad PTC100, USA). The mixture was initially denatured at $94{ }^{\circ} \mathrm{C}$ for $4 \mathrm{~min}$, followed by 30 cycles with $30 \mathrm{~s}$ at $94{ }^{\circ} \mathrm{C}, 45 \mathrm{~s}$ at $62{ }^{\circ} \mathrm{C}, 45 \mathrm{~s}$ at $72{ }^{\circ} \mathrm{C}$ and a $12 \mathrm{~min}$ final extension at $72{ }^{\circ} \mathrm{C}$. PCR products were checked on $2 \%$ of agarose gels followed by staining with $1 \mu \mathrm{g} / \mathrm{mL}$ of ethidium bromide. . The amplified PCR products of $198 \mathrm{bp}$ were digested with Hinfl (NEB UK) restriction enzyme according to manufacturer's specifications. The restriction digestion products were separated on a $3 \%$ agarose gel and visualized by ethidium bromide staining (Figure 1).

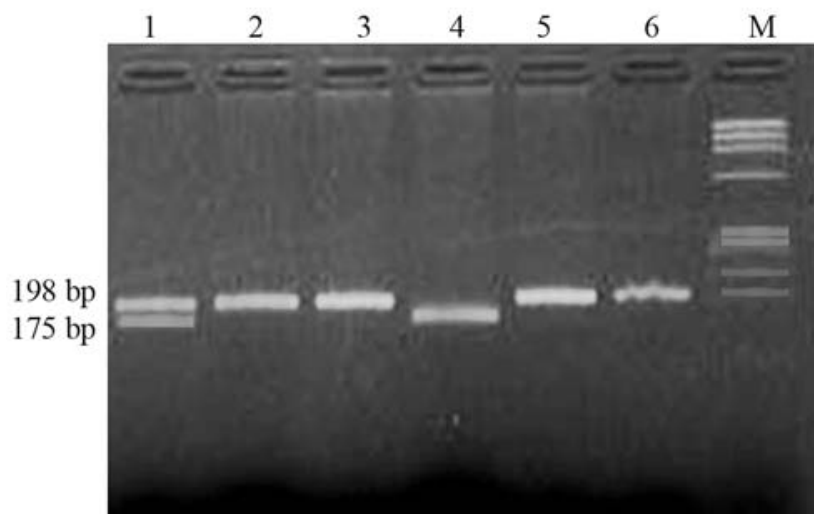

Figure 1 - Detection of MTHFR polymorphism. Lanes 2, 3, 5 and 6 showing wild type (CC) genotype, lane 1 showing mutant heterozygous (CT) genotype and lane 4 showing mutant homozygous (TT) genotype, M showing molecular weight Marker.

\section{Biochemical analyses}

Fasting venous blood from patients and controls were collected in plain vials in order to analyze triglyceride (TG) levels. These levels were measured by lipoprotein lipaseperoxidase (Fossati and Prencipe, 1982), those of total cholesterol (TC) by cholesterol oxidase (Allain et al., 1974) and those of high density lipoprotein (HDL) by phosphotungstate magnesium chloride methodology (Lopes-Virella et al., 1977). Very low density lipoprotein (VLDL) and low density lipoprotein (LDL) levels were calculated indirectly by means of the Friedwald formula (Friedewald et al., 1972) as (VLDL-C $=\mathrm{TG} / 5$ provided $\mathrm{TG}=400 \mathrm{mg} / \mathrm{dL})$ and LDL-C $=$ TC $-($ HDL-C + VLDL-C). Total plasma homocysteine levels were determined in 87 patients and 79 controls by enzyme linked immunoassay (Microplate EIA Homocysteine BioRad, USA). The assay method was based on enzymatic conversion of homocysteine to S-adenosyl homocysteine, followed by quantification of S-adenosylL-homocysteine by an enzyme- linked immunoassay (Frantzen et al., 1998).

\section{Statistical analysis}

Genotype and allele frequencies in CAD and control groups were compared by Chi square testing. The characteristics of patients and controls were evaluated by comparing biochemical findings using the Student $t$-test. Additionally, we performed multiple logistic regression model testing on the interaction of genotype and different classical CAD risk factors. All analyses were performed using SPSS v.11.5 (SPSS Inc., Chicago, USA) statistical analysis software. A two-tailed $p$ value of $p<0.05$ was considered statistically significant.

\section{Results}

The study group included 329 angiographically proven CAD patients [ 80 with myocardial infarction (MI), and the remaining 249 with no past reference], and 331 in- 
dividuals as controls with no clinical history of CAD. The clinical and demographic data of patients and controls are presented in Table 1. Classical risk factors, viz., diabetes, hypertension, smoking and family history were significantly higher in the CAD group than in the control. The value of HDL- cholesterol was significantly lower in CAD patients than in controls, although serum triglyceride, total cholesterol, LDL-cholesterol, VLDL-cholesterol and homocysteine levels were found to be significantly higher in the former.

Allele and genotype frequencies in both patient and control group are described in Table 2. The distribution of genotypes within each group was in Hardy-Weinberg equilibrium. We found the prevalence of the CT genotype to be $11.5 \%$ in the control and $18.2 \%$ in the patient group, whereas almost similar mutant homozygous frequencies $(1.5 \%$ and $2.8 \%)$ were observed in controls and patients, respectively. $\mathrm{T}$ allele frequency was significantly higher in the patient group $(11.9 \%)$ than the control $(7.3 \%)$ $(\mathrm{p}=0.004$, OR $1.7595 \%$ CI 1.16-2.55). On compiling a subgroup of MI and non-MI patients, we found that 63 out of $80 \mathrm{MI}$ patients $(78.6 \%)$ presented a CC genotype, 13 $(16.25 \%)$ a CT genotype, and $4(5.0 \%)$ were homozygous for the $\mathrm{T}$ allele (TT genotype). $\mathrm{C}$ and $\mathrm{T}$ allele frequencies were $87 \%$ [139] and 13\% [21], respectively, in the MI patient group. This indicates a significant association of the $\mathrm{T}$ allele with myocardial infarction in patients in contrast to control $[\mathrm{p}=0.016$ (Fisher exact), OR 1.93 (95\% CI $1.08-3.44)]$.

When we assessed the severity of the disease in terms of the number of vessels involved in CAD and MTHFR polymorphism, interestingly we found no variation in $\mathrm{T}$ allele prevalence in either one, two or three vessels $[12.7 \%$, $10.0 \%$ and $11.0 \%$, respectively] with stenosis in a CAD patient. Similarly findings were observed with homocysteine levels (Table 3). Significantly high levels of homocysteine were observed in the patient group as compared to the control, irrespective of the genotypes involved (CC, CT and TT) (Table 3).

On performing multiple logistic regression analysis; to see the influence of various risk factors on CAD precipitation (Table 4), we found that, in the case of diabetes, hypertension, smoking, triglyceride and HDL-cholesterol, this was significantly variable for $\mathrm{CAD}$. We additionally observed that an increase to $10 \mathrm{mg} / \mathrm{dL}$ in Triglyceride, Total cholesterol and LDL-cholesterol, will increase the risk of CAD by 1.3 times, 1.01 times and 1.08 times, respectively, whereas a $10 \mathrm{mg} / \mathrm{dL}$ decrease in HDL-cholesterol

Table 1 - Characteristics of controls and patients.

\begin{tabular}{lccc}
\hline Characteristics & Controls & CAD Patients & p-value \\
\hline $\mathrm{N}$ & 331 & 329 & - \\
Age & $53.18 \pm 9.18^{*}$ & $57.09 \pm 9.66^{*}$ & 0.217 \\
Sex (M:F) & $245: 86$ & $260: 69$ & 0.142 \\
BMI & $25.12 \pm 3.12^{*}$ & $25.54 \pm 2.97 *$ & 0.077 \\
Diabetic: nondiabetic & $82: 249$ & $142: 187$ & 0.000 \\
Hypertensive: nonhypertensive & $76: 255$ & $156: 173$ & 0.000 \\
Smoker: nonsmoker & $33: 299$ & $66: 263$ & 0.000 \\
Positive family history: negative family history & $04: 329$ & $13: 316$ & $0.028^{* *}$ \\
Triglyceride $(45-150 \mathrm{mg} / \mathrm{dL})$ & $95.75 \pm 27.95^{*}$ & $165.04 \pm 81.33^{*}$ & 0.000 \\
Total Cholesterol $(125-250 \mathrm{mg} / \mathrm{dL})$ & $154.70 \pm 39.73^{*}$ & $170.29 \pm 48.56^{*}$ & 0.000 \\
HDL-cholesterol $(23-60 \mathrm{mg} / \mathrm{dL})$ & $38.34 \pm 7.79^{*}$ & $36.51 \pm 7.01^{*}$ & 0.002 \\
LDL-cholesterol $(92-148 \mathrm{mg} / \mathrm{dL})$ & $97.82 \pm 31.72^{*}$ & $103.99 \pm 43.67 *$ & 0.039 \\
VLDL-cholesterol $(10-30 \mathrm{mg} / \mathrm{dL})$ & $19.59 \pm 6.65^{*}$ & $29.80 \pm 13.90^{*}$ & 0.000 \\
Homocysteine $(5-15 \mu \mathrm{M} / \mathrm{L})$ & $11.11 \pm 4.39$ & $16.05 \pm 8.51$ & 0.000 \\
\hline
\end{tabular}

*Mean $\pm \mathrm{SD},{ }^{* *} \mathrm{p}$-value (Yates correction).

Table 2 - Distribution of genotype and allele frequencies in patients and controls.

\begin{tabular}{lccccc}
\hline Genotype/Allele & Control $(\mathrm{N}=331)$ & Patient $(\mathrm{N}=329)$ & OR & p-value & $95 \%$ CI \\
\hline CC & $288(87.0 \%)$ & $260(79.0 \%)$ & & & 0.054 \\
CT & $38(11.5 \%)$ & $60(18.20 \%)$ & & & \\
TT & $5(1.5 \%)$ & $9(2.8 \%)$ & & 0.004 & $1.16-2.55$ \\
C allele & $614(92.7 \%)$ & $580(88.1 \%)$ & 1.75 & & \\
T allele & $48(7.3 \%)$ & $72(11.9 \%)$ & & \\
\hline
\end{tabular}


Table 3 - Plasma homocysteine levels in patients and controls.

\begin{tabular}{lccc}
\hline & $\begin{array}{c}\text { Homocysteine } \\
\text { level* controls } \\
(\mathrm{N}=79)\end{array}$ & $\begin{array}{c}\text { Homocysteine } \\
\text { level* patients } \\
(\mathrm{N}=87)\end{array}$ & p-value \\
\hline CC Genotype & $11.86 \pm 3.88(66)$ & $14.42 \pm 8.62(56)$ & 0.000 \\
CT Genotype & $11.094 \pm 7.11(9)$ & $18.64 \pm 7.06(25)$ & 0.000 \\
TT Genotype & $16.1788 \pm 3.96(4)$ & $20.59 \pm 10.07(6)$ & 0.000 \\
1 vessel & - & $17.60 \pm 9.47(32)$ & \\
2 vessel & - & $15.15 \pm 6.56(21)$ & 0.437 \\
3 vessel & - & $15.15 \pm 8.63(34)$ & \\
\hline
\end{tabular}

*Values in (Mean $\pm \mathrm{SD})$; () number.

Table 4 - Multivariable logistic regression analysis between controls and patients.

\begin{tabular}{lcccc}
\hline Variable & B & p-value & OR & $95 \%$ CI \\
\hline BMI & 0.049 & 0.168 & 1.050 & $0.980-1.125$ \\
Diabetes & 0.844 & 0.000 & 2.326 & $1.480-3.655$ \\
Hypertension & 0.923 & 0.000 & 2.490 & $1.589-3.901$ \\
Smoking & 0.713 & 0.017 & 2.040 & $1.136-3.664$ \\
Family history & 1.004 & 0.172 & 2.728 & $0.649-11.45$ \\
Triglyceride & 0.033 & 0.000 & 1.034 & $1.021-1.05$ \\
Total cholesterol & 0.002 & 0.796 & 1.002 & $0.984-1.021$ \\
HDL-cholesterol & -0.110 & 0.000 & 0.895 & $0.861-0.931$ \\
LDL-cholesterol & 0.011 & 0.260 & 1.011 & $0.992-1.031$ \\
VLDL-cholesterol & -0.022 & 0.450 & 0.979 & $0.926-1.035$ \\
MTHFR CT genotype & 0.295 & 0.319 & 1.343 & $0.752-2.396$ \\
MTHFR TT genotype & 0.236 & 0.751 & 1.226 & $0.295-5.423$ \\
\hline
\end{tabular}

leads to a 2.5 times greater risk of CAD. This indicates that HDL-C is more crucial for CAD. Furthermore a concurrent increase in MTHFR CT and TT genotypes leads to an even greater $\mathrm{CAD}$ risk (1.3 times and 1.2 times, respectively) than $\mathrm{CC}$ genotype.

\section{Discussion}

The implication of the MTHFR gene in CAD pathogenesis has been extensively studied in several ethnic groups. We found a significantly higher frequency of $\mathrm{T}$ alleles in CAD patients than in controls. OR in this group was 1.75. Other epidemiological studies that estimated the risk of CAD associated with the T allele showed conflicting results. Notwithstanding, Kerkeni et al. (2006) and Alam et al. (2008) found this substitution to be a significant risk factor. On summarizing the results from 8 studies, Kluijtmans et al. (1996) encountered no significant difference for the $\mathrm{T}$ allele, although they reported higher frequencies (31.8\% and $29 \%$ in patient and control group respectively).

We found the $\mathrm{T}$ allele to be significantly associated with myocardial infarction $(\mathrm{p}=0.016, \mathrm{OR} 1.93,95 \% \mathrm{CI}$
1.08-3.44). This finding is consistent with a previous report (Gülec et al., 2001) in which MTHFR C677T transition was found to be a risk factor for premature MI. On the other hand, other authors ( Anderson et al., 1997; Hsu et al., 2001) reported insignificant differences for the $T$ allele between MI subjects and the control group. We observed almost equal frequencies for the CC, CT and TT genotypes, irrespective of one-, two- or three-vessel-stenosis, Our findings are in accordance with previous reports (Van Bockxmeer et al., 1997; Kerkeni et al., 2006; Rassoul et al., 2008), in which insignificant association was observed. Nevertheless, for Morita et al. (1997) the association was significant. Furthermore, we noted that the severity of the disease is independent of homocysteine levels. Likewise, Wang et al. (1999) found no correlation between the level of homocysteine and severity of the disease, whereas Rassoul et al. (2008), on the contrary, discovered a positive association.

In our study, the average homocysteine level was significantly higher in the patient group than in the control. This is in agreement with observations by other investigators (Evans et al., 1997; Kerkeni et al., 2006). The finding of a significant correlation between 5,10 methylene tetrahydrofolate reductase enzyme activity and MTHFR genotypes (Frosst et al., 1995) (70\% reduced activity in the TT genotype and $35 \%$ reduced activity in the CT genotype) implies elevated homocysteine levels in these two genotypes.

A previous study by Alam et al. (2008) on 100 coronary artery cases and 100 controls, also from North India, demonstrated the positive association of MTHFR (C677T) gene polymorphism. The present study is in agreement, although with a larger-sized sample, and undertaken with certain restrictions, such as using a single MTHFR genetic marker (C677T). Thus, further polymorphic MTHFR markers need to be evaluated, together with the other genetic markers involved in the Homocysteine pathway for predisposition to the disease.

Coronary artery disease is a complex disorder where environmental and genetic markers both play an important role.

\section{Acknowledgments}

The authors wish to thank the Sanjay Gandhi PostGraduate Institute of Medical Sciences (SGPGIMS), Lucknow, for providing the infrastructure. Rajneesh Tripathi is thankful to the Department of Biotechnology (DBT), New Delhi, India for the award of his Senior Research fellowship.

\section{References}

Alam MA, Husain SA, Narang R, Chauhan SS, Kabra M and Vasisht S (2008) Association of polymorphism in the thermolabile 5, 10-methylene tetrahydrofolate reductase gene and hyperhomocysteinemia with coronary artery disease. Mol Cell Biochem 310:111-117. 
Allain CC, Poon LS, Chan CSG, Richmond W and Fu PC (1974) Enzymatic determination of total serum cholesterol. Clin Chem 20:470-478.

Anderson JL, King GJ, Thomson MJ, Todd M, Bair TL, Muhlestein JB and Carlquist JF (1997) A mutation in the methylenetetrahydrofolate reductase gene is not associated with increased risk for coronary artery disease or myocardial infarction. J Am Coll Cardiol 30:1206-1211.

Andreassi MG, Botto N, Cocci F, Battaglia D, Antonioli E, Masetti S, Manfredi S, Colombo MG, Biagini A and Clerico A (2003) Methylenetetrahydrofolate reductase gene C677T polymorphism, homocysteine, vitamin B12, and DNA damage in coronary artery disease. Hum Genet 112:171-177.

Arruda VR, Siqueira LH, Gonçalves MS, von Zuben PM, Soares MC, Menezes R, Annichino-Bizzacchi JM and Costa FF (1998) Prevalence of the mutation C677 > T in the methylene tetrahydrofolate reductase gene among distinct ethnic groups in Brazil. Am J Med Genet 78:332-335.

Bova I, Chapman J, Sylantiev C, Korczyn AD and Bornstein NM (1999) The A677V methylenetetrahydrofolate reductase gene polymorphism and carotid atherosclerosis. Stroke 30:2180-2182.

Doevendans PA, Jukema W, Spiering W, Defesche JC and Kastelein JJ (2001) Molecular genetics and gene expression in atherosclerosis. Int J Cardiol 80:161-172.

Evans RW, Shaten BJ, Hempel JD, Cutler JA and Kuller LH (1997) Homocysteine and risk of cardiovascular disease in multiple risk factor interventional trial. Arterioscler Thromb Vasc Biol 17:1947-1953.

Fauci AS, Braundwald E, Kasper DL, Hauser SL, Longo DL, Jameson JL and Loscalzo J (2008) The pathogenesis of atherosclerosis. In: Harrison's Principle of Internal Medicine. $17^{\text {th }}$ edition. Mc GrawHill, New York, pp 1425-1433.

Fossati P and Prencipe L (1982) Serum triglyceride determination calorimetrically with an enzyme that provides hydrogen peroxide. Clin Chem 28:2077-2082.

Frantzen F, Faaren AL, Alfheim I and Nordhei AK (1998) Enzyme conversion immunoassay for determining total homocysteine in plasma or serum. Clin Chem 44:311-316.

Friedewald WT, Levy RI and Fredrickson DS (1972) Estimation of the concentration of low-density lipoprotein cholesterol in plasma, without use of the preparative ultracentrifuge. Clin Chem 18:499-502.

Frosst P, Blom HJ, Milos R, Goyette P, Sheppard CA, Matthews RG, Boers GJ, den Heijer M, Kluijtmans LA, van den Heuvel LP et al. (1995) A candidate genetic risk factor for vascular disease: A common mutation in methylenetetrahydrofolate reductase gene. Nat Genet 10:111-113.

Gülec S, Aras O, Akar E, Tutar E, Omürlü K, Avci F, Dinçer I, Akar N and Oral D (2001) Methylenetetrahydrofolate reductase gene polymorphism and risk of premature myocardial infarction. Clin Cardiol 24:281-284.

Hankey GJ and Eikelboom JW (1999) Homocysteine and vascular disease. Lancet 354:407-413.

Hofmann MA, Lalla E, Lu Y, Gleason MR, Wolf BM, Tanji N, Ferran Jr LJ, Kohl B, Rao V and Kisiel W et al. (2001) Hyperhomocysteinemia enhances vascular inflammation and accelerates atherosclerosis in a murine model. J Clin Invest 107:675-683.

Hsu LA, Ko YL, Wang SM, Chang CJ, Hsu TS, Chiang CW and Lee YS (2001) The C677T mutation of the methylenete- trahydrofolate reductase gene is not associated with the risk of coronary artery disease or venous thrombosis among Chinese in Taiwan. Hum Hered 51:41-45.

Kerkeni M, Addad F, Chauffert M, Myara A, Gerhardt M, Chevenne D, Trivin F, Farhat MB, Miled A and Maaroufi K (2006) Hyperhomocysteinaemia, methylenetetrahydrofolate reductase polymorphism and risk of coronary artery disease. Ann Clin Biochem 43:200-206.

Kluijtmans LA, van den Heuvel LP, Boers GH, Frosst P, Stevens EM, van Oost BA, den Heijer M, Trijbels FJ, Rozen R and Blom HJ (1996) Molecular genetic analysis in mild hyperhomocysteinemia: A common mutation in the methylenetetrahydrofolate gene is as a genetic risk factor for cardiovascular disease. Am J Hum Genet 58:35-41.

Lobo A, Naso A, Arheart K, Kruger WD, Abou-Ghazala T, Alsous F, Nahlawi M, Gupta A, Moustapha A and van Lente F et al. (1999) Reduction of homocysteine levels in coronary artery disease by low-dose folic acid combined with vitamins B6 and B12. Am J Cardiol 83:821-825.

Lopes-Virella MF, Stone P, Ellis S and Colwell JA (1977) Cholesterol determination in high density lipoprotein separated by three different methods. Clin Chem 23:882-888.

Morita H, Taguchi J, Kurihara H, Kitaoka M, Kaneda H, Kurihara Y, Maemura K, Shindo T, Minamino T and Ohno M et al. (1997) Genetic polymorphism of 5, 10-methylenetetrahydrofolate reductase (MTHFR) as a risk factor for coronary artery disease. Circulation 95:2032-2036.

Poncz M, Solowiejczyk D, Harpel B, Mory Y, Schwartz E and Surrey S (1982) Construction of human gene libraries from small amounts of peripheral blood: Analysis of beta-like globin genes. Hemoglobin 6:27-36.

Rassoul F, Richter V, Hentschel B, Geisel J, Herrmann W and Kuntze T (2008) Plasma homocysteine levels \& 677C-T methylenetetrahydrofolate reductase gene polymorphism in patients with coronary artery disease of different severity. Indian J Med Res 127:154-158.

Robinson K, Mayer EL, Miller DP, Green R, van Lente F, Gupta A, Kottke-Marchant K, Savon SR, Selhub J and Nissen SE (1995) Hyperhomocysteinemia and low pyridoxal phosphate: Common and independent reversible risk factors for coronary artery disease. Circulation 92:2825-2830.

Tyagi SC (1998) Homocysteine redox receptor and regulation of extracellular matrix components in vascular cells. Am J Physiol 274:C396-405.

Van Bockxmeer FM, Mamotte CDS, Vasikaran SD and Taylor RR (1997) Methylenetetrahydrofolate reductase gene and coronary artery disease. Circulation 95:21-23.

Wang XL, Duarte N, Cai H, Adachi T, Sim AS, Cranney G and Wilcken DE (1999) Relationship between total plasma homocysteine, polymorphisms of homocysteine metabolism related enzymes, risk factors and coronary artery disease in the Australian hospital-based population. Atherosclerosis 146:133-140.

Welch GN, Upchurch Jr G and Loscalzo J (1997) Hyperhomocyst(e)inemia and atherothrombosis. Ann N Y Acad Sci 811:48-58.

Associate Editor: Francisco Mauro Salzano

License information: This is an open-access article distributed under the terms of the Creative Commons Attribution License, which permits unrestricted use, distribution, and reproduction in any medium, provided the original work is properly cited. 